\title{
Dampak Sosial Ekonomi Pengelolaan Ekowisata Mangrove Kampoeng Kepiting Terhadap Nelayan Desa Tuban Kabupaten Badung
}

I Gusti Made Intan Sanisca Wardani a,1, I Putu Anoma,2

1geksanisca@gmail.com, 2putuanom@unud.ac.id

a Program Studi S1 Destinasi Pariwisata, Fakultas Pariwisata,Universitas Udayana, Jl. Dr. R. Goris, Denpasar, Bali 80232 Indonesia

\section{Abstract}

Tourism in each region should be able to provide benefits to the local community, especially the economic benefits. Sustainable tourism, should be intensified in tourism development at this time, because they have a positive impact on society, but it does not negatively impact the natural state. This research was conducted in Ekowisata Mangrove Kampoeng Kepiting, Tuban Village, Badung Regency.

This study used a technique-depth interviews with the head of the fishermen, and the secretary of the fishermen, and using purposive sampling method. This research was conducted with a qualitative descriptive analysis techniques that will be used to describe the results of interviews that have been conducted.

The results of this study, that Ecotourism is managed entirely by a group of fishermen, with the division of tasks to handle all existing activities. Socio-economic impact that occurs by adding the income of fishermen, full employment, building a fishermen economy, changing the mindset of fishermen on the environment, fishermen have the skills, able to organize, and interact well. From the results of this study are expected to be fishermen, to increase the fishing economy, and maintaining the principles which will not be affected to investors, both domestic investors and foreign investors, because the people who should be able to host their own country.

Keywords: ecotourism, management, socio-economic impacts

\section{PENDAHULUAN}

Pariwisata berperan penting dalam pembangunan ekonomi di berbagai negara, sehingga mebuat pariwisata disebut sebagai passport to development, new kind of sugar, tool for regional development, invisible export, non polluting industry (Pitana,2005). Perkembangan pariwisata yang pesat seharusnya mampu mengurangi masalah ekonomi. Pengembangan dan pengelolaan di daerah tujuan wisata diharapkan mampu lebih memperhatikan kondisi lingkungan yang ada serta kesejahteraan masyarakat lokal, bukan hanya terfokus pada keuntungan semata.

Menurut organisasi The Ecotorism Society (Wibowo, 2007) ekowisata merupakan bentuk perjalanan wisata ke daerah alami yang dilakukan dengan tujuan konservasi lingkungan, melestarikan dan mensejahterakan kehidupan masyarakat setempat. Hal ini membuat ekowisata sangat penting untuk dikembangkan, melihat keadaan pembangunan pariwisata yang semakin tidak terkendali, dilihat dari banyaknya pembangunan gedunggedung sebagai sarana pelengkap pariwisata. Kerusakan lingkungan yang mulai terlihat akibat pembangunan adalah di Kawasan Hutan Mangrove, dimana lahannya mulai berkurang akibat dampak dari pembangunan, dan reklamasi. Secara sosial adanya reklamasi akan berdampak kepada kehidupan masyarakat lokal sekitarnya, dan sangat mengganggu segala kegiatan yang ada di kawasan Mangrove dan sekitarnya.

Ekowisata Mangrove Kampoeng Kepiting merupakan salah satu ekowisata yang mulai dikembangakan untuk pemberdayaan nelayan yang menjadi masyarakat lokal Desa Tuban. Ekowisata ini lebih terfokus kepada pemanfaatan kawasan Mangrove dan ekosistem mangrove. Ekowisata ini dikelola oleh kelompok nelayan Wanasari Desa Tuban yang beranggotakan dengan nama kelompok :Ekowisata-Nelayan Wanasari-Tuban, memiliki Jumlah Anggota: 95 orang, terbentuk pada tanggal 07 Agustus 2008, dengan nomer pengukuhan 306/Kpts/Org/5/2008, pengukuhan dilakukan pada tanggal 26 November 2009. Status yang dimiliki kelompok ini yaitu swadaya. Dengan usaha pokok yang dimiliki yaitu budidaya kepiting dan perikanan selain usaha poko ada juga usaha lainnya yaitu jasa ekowisata. (Sumber: data kelompok nelayan wanasari).

Adapun jumlah kunjungan di Ekowisata Mangrove Kampoeng Kepiting, berikut tabelnya: 
Tabel 1

Data Jumlah Pengunjung Ekowisata Mangrove Kampoeng Kepiting

\begin{tabular}{|c|c|c|c|c|}
\hline NO & BULAN & $\begin{array}{c}\text { TAHUN } \\
\mathbf{2 0 1 3}\end{array}$ & $\begin{array}{c}\text { TAHUN } \\
\mathbf{2 0 1 4}\end{array}$ & $\begin{array}{c}\text { TAHUN } \\
\mathbf{2 0 1 5}\end{array}$ \\
\hline 1 & Januari & - & 784 & 1.011 \\
\hline 2 & Februari & - & 816 & 839 \\
\hline 3 & Maret & - & 918 & 1.122 \\
\hline 4 & April & 275 & 1.183 & 917 \\
\hline 5 & Mei & 325 & 1.141 & 1.314 \\
\hline 6 & Juni & 415 & 905 & - \\
\hline 7 & Juli & 511 & 1.050 & - \\
\hline 8 & Agustus & 612 & 1.232 & - \\
\hline 9 & September & 599 & 811 & - \\
\hline 10 & Oktober & 876 & 795 & - \\
\hline 11 & Nopember & 1.135 & 982 & - \\
\hline 12 & Desember & 1.225 & 1.275 & - \\
\hline & Total & $\mathbf{5 . 9 7 3}$ & $\mathbf{1 1 . 8 9 2}$ & $\mathbf{5 . 2 0 3}$ \\
\hline
\end{tabular}

Sumber: Data kunjungan Ekowisata Mangrove Kampoeng Kepiting.

Berdasarkan penjelasan pada Tabel 1. Terlihat bahwa ada peningkatan pada jumlah kunjungan di Ekowisata Mangrove Kampoeng Kepiting, maka dari itu, peneliti ingin mengangkat topik tentang dampak sosial ekonomi pengelolaan Ekowisata Mangrove Kampoeng Kepiting terhadap kelompok nelayan Wanasari Desa Tuban Kabupaten Badung. Penelitian ini sangat penting karena kita mampu mengetahui bagaimana dampak sosial ekonomi yang terjadi dengan adanya Ekowisata Mangrove Kampoeng Kepiting. Penelitian ini diharapkan dapat memberikan manfaat bagi mahasiswa untuk mampu mengaplikasikan konsep-konsep ekowisata yang diperoleh selama mengikuti perkuliahan, khususnya pada mata kuliah ekowisata. Mampu menambah wawasan mahasiswa dalam menganalisis, dan memecahkan masalah kepariwisataan. Selain itu penelitian ini juga diharapkan mampu menjadi acuan bagi para nelayan agar mampu mengelola Ekowisata ini dengan baik, untuk pemerintah, investor dan instansi yang terkait agar mampu membantu dalam meningkatkan kesejahteraan nelayan, serta memberikan dampak positif bagi pengembangan ekowisata.

\section{TINJAUAN PUSTAKA}

Penelitian sebelumnya yang dijadikan referensi dalam penelitian ini adalah jurnal oleh Ni Wayan Vijayanthi Sari (2002) dengan judul
"Pengelolaan Sampah di Kawasan Hutan Mangrove Suwung Teluk Benoa Sebagai Upaya Kebersihan Lingkungan dan Pengembangan Ekowisata Mangrove", penelitian tersebut membahas tentang pengelolaan sampah di Kawasan Hutan Mangrove dengan melibatkan seluruh stakeholders. Penelitian ini memiliki kesamaan lokasi penelitian, namun dengan focus yang berbeda. Penelitian kedua yaitu jurnal oleh Aripin (2005) dengan judul "Pengaruh Kegiatan Pariwisata Terhadap Sosial Ekonomi Masyarakat di Kawasan Bukit Cinta Rawa Pening Kabupaten Semarang", dalam penelitian ini perubahan sosial yang terjadi yaitu sistem kemasyarakatan, jenis pekerjaan masyarakat, penghasilan tambahan, dan pendidikan yang terjamin, kesamaan dengan penelitian yang dilakukan terletak pada focus penelitian yaitu pengaruh terhadap sosial ekonomi.

Konsep yang terdapat dalam penelitian ini yaitu Konsep Pengelolaan menurut Siula dalam Sobri (2009) pengelolaan umumnya dikaitkan dengan aktivitas perencanaan, pengorganisasian, pengendalian, penempatan, pengarahan, pemotivasian, komunikasi, dan pengambilan keputusan yang dilakukan oleh setiap organisasi dengan tujuan untuk mengkoordinasikan berbagai sumber daya yang dimiliki oleh organisasi sehingga akan dihasilkan suatu produk atau jasa secara efisien. Konsep Dampak Sosial Ekonomi menurut Cohen dalam Pitana (2005), Dampak Sosial Ekonomi masyarakat lokal dikategorikan menjadi delapan kelompok besar yaitu, dampak terhadap penerimaan devisa, pendapatan masyarakat, kesempatan kerja, harga-harga, distribusi keuntungan/manfaat, kepemilikan dan kontrol, pembangunan, pendapatan pemerintah, konsep tersebut yang akan digunakan untuk menjawab dampak sosial ekonomi yang terjadi terhadap nelayan.

\section{METODE PENELITIAN}

Lokasi penelitian ini dilakukan di Ekowisata Mangrove Kampoeng Kepiting yang terletak di Jl.Bypass Ngurah Rai no 1 Desa Tuban, Kabupaten Badung, Provinsi Bali. Lokasi ini dipilih karena lokasi tersebut merupakan Ekowisata yang sedang berkembang, dan dikelola oleh kelompok nelayan, demi mensejahterakan kehidupan nelayan. 
Ruang lingkup dalam penelitian ini guna memperjelas dan membatasi penelitian ini yaitu bentuk pengelolaan atraksi yang dilakukan oleh nelayan, dampak sosial ekonomi yang terjadi setelah terbentuknya ekowisata ini berupa, pendapatan masyarakat, kesempatan kerja, keuntungan, kepemilikan, serta interaksi. Jenis data dalam penelitian ini yaitu data kualitatif berupa informasi yang didapatkan dari informan seperti sejarah, pengelolaan, serta dampak sosial ekonomi yang terjadi terhadap nelayan, data kuantitatif berupa jumlah nelayan, serta jumlah kunjungan ke Ekowisata Mangrove Kampoeng Kepiting. Sumber data yang digunakan yaitu data primer berasal dari data yang diperoleh langsung di lapangan dan data sekunder yang diperoleh melalui internet berupa dokumen grafis. Teknik pengumpulan data yang digunakan ada empat berdasarkan Noor (2011) yaitu observasi pada lokasi penelitian, wawancara mendalam kepada pengelola, dokumentasi berupa laporan kunjungan, dan foto-foto di lokasi penelitian, serta studi pustaka referensi yang terkait dengan penelitian. Penentuan informan dalam penelitian ini menggunakan teknik purposive sampling, dengan pertimbangan informan yang sudah ditentukan sebelumnya memiliki pengetahuan mengenai Ekowisata Mangrove Kampoeng Kepiting, informan yang dimaksud dalam penelitian ini adalah ketua dan skretaris kelompok nelayan Wanasari. Penelitaian ini menggunakan teknik analisis deskriptif kualitatif, dimana peneliti mendreskripsikan dampak sosial ekonomi yang terjadi terhadap nelayan setelah terbentuknya Ekowisata Mangrove Kampoeng Kepiting.

\section{HASIL DAN PEMBAHASAN}

Ekowisata Mangrove Kampoeng Kepiting merupakan ekowisata yang terbentuk dengan tujuan utama untuk memperkenalkan tentang pelestarian dan pembudidayaan ekosistem Hutan Mangrove. Luas Ekowisata Mangrove Kampoeng Kepiting ini sekitar 4-5 hektar dari keseluruhan luas Hutan Mangrove dikawasan Tuban. Terdapat program paket wisata yang disediakan pada ekowisata ini yaitu: pengenalan sistem budidaya kepiting bakau, pelepasan bibit kepiting bakau, tours kedalam Hutan Mangrove, penanaman bibit pohon bakau, tracking Hutan Mangrove.
Terbentuknya Ekowisata Mangrove Kampoeng Kepiting berawal dibuatnya yayasan dengan nama Yayasan Taman Wana Sari, dan mampu memperoleh prestasi yang menjadi pendorong bagi perkembangan industri udang dan kepiting secara nasional. Keberhasilan yang diraih yaitu dengan diterapkan teknik budidaya udang dengan cara tambak, sehingga hal tersebut dapat mengatasi kesulitan ekonomi. Pengukuhan nelayan Wanasari Tuban diterima oleh pemerintah Kabupaten Badung pada tanggal 26 November 2009 , setelah itu nelayan juga berhasil mengkaji teknik budidaya kepiting bakau dengan sistem keramba tancap yang ramah lingkungan. Keramba kepiting ini telah berkembang dan mampu meningkatkan pendapatan masyarakat pesisir dan nelayan di sekitar Tuban dalam waktu singkat. Tahun 2011 usaha ini mulai berkembang dan dijadikan percontohan oleh daerah lainnya di Indonesia. Melihat kekayaan alam yang mampu dikembangkan, muncul ide dari kelompok Nelayan Wanasari untuk membuat sebuah ekowisata, dengan berprinsip tidak merusak ekosistem dan habitat Hutan Mangrove.

Sistem pengelolaan Ekowisata Mangrove Kampoeng Kepiting ini melibatkan seluruh nelayan dalam mengelola masing-masing program yang ada. dengan membentuk struktur organisasi dari ketua, sampai anggota dari masing-masing kelompok, dengan tugas dan perannya masing-masing.

Terdapat program-program yang didalamnya dikelola oleh nelayan dengan membentuk sebuah kelompok, dan pembagian masing-masing tugas untuk nelayan:

\section{Budidaya Kepiting}

Program budidaya kepiting ini dikelola oleh kelompok nelayan yang dibentuk untuk menangani pembudidayaan kepiting, yang akan digunakan di Restoran Kampoeng Kepiting, serta tetap menjaga kelestraian kepiting bakau. Dalam program ini terdapat kegiatan mulai dari pembibitan, perawatan, hingga pemasaran kepiting bakau. Program ini terdiri dari lima kelompok nelayan yang bertugas didalamnya, masing-masing kelompok terdiri dari lima sampai sepuluh anggota.

2. Restoran (Program Kuliner)

Program kuliner ini yaitu Restoran yang ada di dalam kawasan Ekowisata Mangrove 
Kampoeng Kepiting. Restoran Kampoeng Kepiting yang menjadi wadah dalam memasarkan hasil budidaya serta menjual tangkapan nelayan yang masih melaut. Restoran ini juga menjadi penghasil dana terbesar untuk mendanai keseluruhan program yang ada di Ekowisata Mangrove Kampoeng Kepiting. Keuntungan hasil dari penjual di restoran ini diserahkan ke nelayan dan dibagikan ke masing-masing program.

3. POKLAHSAR (Kelompok Pengolah Pemasaran)

Poklahsar merupakan kelompok yang beranggotakan wanita, dan mereka merupakan ibu-ibu nelayan yang terbagi menjadi tiga kelompok dengan tugasnya masing-masing yaitu kelompok pengolah buah mangrove. Kelompok ini beranggotakan sepuluh orang wanita yang bertugas mengolah buah mangrove menjadi makanan dan minuman seperti, keripik mangrove, coklat mangrove, sirup buah mangrove, jus buah mangrove, selai mangrove, permen mangrove dan kue. Adapun bahan makanan seperti beras dan tepung yang terbuat dari buah lindur, salah satu tanaman yang terdapat di Mangrove. Serta produk kecantikan seperti sabun mangrove, dan lulur mangrove. Selain itu terdapat juga sabun untuk mencuci perabotan rumah tangga yang terbuat dari buah mangrove. Kelompok pengolah ikan, dengan beranggotakan sepuluh orang wanita yang bertugas mengolah ikan hasil tangkapan nelayan menjadi berbagai macam jenis makanan. Selanjutnya kelompok pengolahan non beras dengan jumlah anggota sepuluh orang wanita, yang bertugas mengolah bahan makanan selain beras seperti umbi-umbian.

Semua produk-produk yang di hasilkan oleh kelompok ini akan dipasarkan kepada wisatawan, dan dijula di toko-toko yang terdapat di dekat tempat parkir di Ekowisata Mangrove Kampoeng Kepiting.

4. POKMASWAS

Pokmaswas merupakan kelompok dengan beranggotakan sepuluh orang yang bertugas mengawasi segala bentuk kegiatan yang ada di Kawasan Mangrove, Desa Tuban, agar tidak ada kegiatan yang dialkukan secara illegal, dan mampu merusak lingkungan, khususnya Kawasan Hutan Mangrove.

5. Seni Budaya

Program seni budaya memiliki kelompok yang memegang tugas sesuai dengan keahliannya masing-masing, yaitu: terdapat kelompok rindik (alat musik tradisional) yang beranggotakan lima orang, kelompok ini biasanya akan tampil pada hari sabtu dan minggu pada siang hari, dengan waktu tampil dua jam. Kelompok tari kecak, beranggotakan 60-70 orang yang berasal dari nelayan dan anggota keluarga nelayan. Tarian kecak ini akan ditampilkan pada hari sabtu dan minggu pada malam hari. Selain dua pertunjukan tersebut, akan dibentuk kelompok sanggar tari, guna mewadahi bakat-bakat anak nelayan dalam berseni budaya. Tarian dan music tersebut dipentaskan pada hari yang sudah ditentukan, dan kelompok nelayan yang pentas akan diberikan gaji persekali mementaskan keahliannya.

6. Pariwisata

Pariwisata di Ekowisata Mangrove Kampoeng Kepiting dikemas dalam bentuk paket tour, didalamnya terdapat kegiatan edukasi dan memfokuskan pada kegiatan konservasi. Paket tour tersebut terdiri dari: a. Canoe tour clean mangrove: kegiatan ini mengajak wisatawan untuk mengelilingi hutan mangrove dan membersihkan kawasan hutan mangrove dengan menaiki kano.

b. Mangrove tour with traditional boat: kegiatan ini mengajak wisatawan untuk mengelilingi hutan mangrove dengan peharu tradisional milik nelayan.

c. Canoe fishing mangrove: dalam kegiatan ini wisatawan akan memancing di kawasan Hutan Mangrove dengan menaiki kano.

d. Fishing mangrove with traditional boat: kegiatan ini wisatawan akan memancing dengan menggunakan perahu tradisional milik nelayan.

e. Tours pelepasan bibit kepiting: wisatawan akan diajak untuk berkeliling Hutan Mangrove dan melepaskan bibit kepiting bakau.

$f$. Tours keramba dan mangrove tours: dalam kegiatan ini wisatawan diajak berkeliling melihat keramba kepiting, serta bekeliling Hutan Mangrove. 
g. Mangrove tours education: memberikan informasi kepada wisatawan mengenai Mangrove, sekaligus berkeliling Hutan Mangrove.

h. Paket pembuatan bibit mangrove: kegiatan ini mengajak wisatawan untuk membuat bibit pohon mangrove.

i. Paket penanaman pohon mangrove: kegiatan ini mengajak wisatawan untuk menanam pohon mangrove di kawasan hutan mangrove.

$j$. Paket pengolahan buah mangrove: dalam kegiatan ini wisatawan akan diajak untuk membuat olahan dari tanaman mangrove.

7. Mangrove Edukasi dan Konservasi

Prorgam Mangrove Edukasi dan Konservasi memiliki jumlah anggota delapan orang yang bertugas, melakukan pembibitan, penanaman dan perawatan mangrove, termasuk membersihkan kawasan hutan mangrove demi perkembangan tanaman mangrove yang baik, karena butuh waktu minimal satu tahun untuk perawatan mangrove agar benar-benar bisa tumbuh dengan baik. Saat ini kurang lebih ada lima jenis bibit tanaman mangrove yang dikembangkan.

\section{Dampak Sosial Ekonomi}

Dampak social ekonomi yang terjadi terhadap nelayan Wanasari, Desa Tuban Kabupaten Badung, setelah terbentuknya Ekowisata Mangrove Kmpoeng Kepiting, yaitu:

1. Adanya dampak terhadap pendapatan masyarakat dapat dilihat dari adanya paket tour di ekowisata ini yang menjadi salah satu sumber pendapatan untuk nelayan, dikarenakan nelayan, ikut terjun langsung dalam kegiatan tersebut, mulai dari penyediaan perahu nelayan, sampai menjadi guide lokal bagi wisatawan. Tarif yang dikenakan pada paket wisata ini hanya diambil $10 \%$ untuk dimasukan ke kas nelayan dari tarif keseluruhan, dan sisanya akan diberikan langsung kepada nelayan yang menjadi guide, ataupun nelayan yang perahunya digunkanan dalam kegiatan.

2. Membangun Perekonomian nelayan.

Kesulitan ekonomi yang pernah dialami oleh nelayan, membuat nelayan berusaha mencari jalan keluar terhadap masalahnya. Nelayan mencoba melakukan teknik budidaya udang dengan cara tambak, serta mulai melakukan budidaya kepiting bakau dengan sistem keramba dan, mampu mendulang kesuksesan, hal tersebut mampu mengatasi masalah ekonomi yang dialami nelayan. Nelayan yang masih melaut bisa menjual hasil tangkapannya di Restoran yang ada di Ekowisata Mangrove Kampoeng Kepiting.

3. Tersedianya lapangan kerja.

Ekowisata Mangrove Kampoeng Kepiting ini, memberikan peluang lapangan kerja bukan hanya untuk nelayan tetapi kepada seluruh anggota keluarga nelayan. Ada tiga tahapan perekrutan karyawan, yaitu: diutamakan berasal dari anggota keluarga nelayan, yang kedua berasal dari Desa Adat Tuban, dan yang ketiga berasal dari luar desa adat.

4. Perubahan mata pencaharian

Nelayan yang awalnya bekerja dilaut menangkap ikan, saat ini beralih menjadi nelayan yang membudidayakan kepiting bakau serta mengelola Ekowisata, namun tidak semua nelayan berhenti untuk melaut, ada beberapa nelayan yang masih bekerja sebagai nelayan tradisional.

5. Perubahan pola pikir nelayan

Dahulu nelayan memanfaatkan tanaman mangrove sebagai bahan bakar, dan daun dari tanaman mangrove dijadikan makanan ternak, jika hal tersebut terus berlanjut maka akan merusak ekosistem mangrove., karena pohon mangrove yang selalu ditebang serta diambil daunnya, sehingga tanaman mangrove kan berkurang. Saat ini nelayan mulai sadar akan pentingnya kawasan Hutan Mangrove, bukan hanya untuk kelestarian lingkungan namun juga untuk kesejahteraan nelayan sendiri, sehinggan nelayan mulai merawat serta menjaga kelestarian Hutan Mangrove.

6. Pengembangan kemampuan.

Adanya Ekowisata ini membuat seluruh nelayan memiliki kemampuan untuk mengelol, di ekowisata ini diadakan pemberdayaan nelayan agar nelayan mampu menciptakan suatu produk yang bermanfaat, serta mampu menciptakan inovasi baru guna mengembangkan ekowisata ini menjadi lebih baik lagi. Nelayan diberikan informasi mengenai pembibitan mangrove, pembibitan kepiting, serta edukasi mengenai pengelolaan ekowisata. Selain itu nelayan juga mampu berorganisasi dengan sesame 
kelompok, masyarakat serta para akademisi yang sering melakukan penelitian di Ekowisata Mangrove Kampoeng Kepiting. Nelayan mampu berinteraksi dengan baik dengan nelayan sendiri ataupun dengan wisatawan.

\section{SIMPULAN DAN SARAN}

Simpulan yang dapat ditarik dari pembahasan sebelumnya, yaitu bentuk pengelolaan yang ada di Ekowisata Mangrove Kampoeng Kepiting adalah, nelayan di bagi dalam beberapa kelompok dan diberikan tugas masing-masing dalam mengelola programprogram yang sudah mereka bentuk bersama.. Dengan kerja keras yang sudah dilakukan, nelayan mampu mengatasi kesulitan ekonomi yang dialami. Dampak sosial ekonomi yang terjadi tidak terlihat signifikan, tetapi dengan adanya ekowisata ini, perekonomian nelayan sudah semakin membaik. Dampak social ekonomi yang terjadi yaitu, adanya pendapatan masyarakat, mampu membangun perekonomian nelayan, tersedianya lapangan pekerjaan, adanya perubahan mata pencaharian, perubahan pola pikir, serta pengembangan kemampuan.

Agar ekowisata ini dapat lebih berkembang, disarankan kepada pihak pengelola, untuk lebih meningkatkan promosi khsusnya dalam paket tour yang disediakan, mengadakan pelatihan-pelatihan kepada nelayan, untuk pemerintah agar mampu mendukung ekowisata ini agar mampu menjadi ekowisata yang lebih baik lagi kedepannya, untuk penelitian selanjutnya, penelitian ini terbatas pada fokus penelitian serta waktu, selnjutnya pihak akademisi bisa melakukan penelitian yang berkaitan dengan kegiatan budidaya dan konservasi di Ekowisata Mangrove Kampoeng Kepiting.

\section{Daftar Pustaka:}

Aripin.2005.Pengaruh Kegiatan Pariwisata Tehadap Sosial Ekonomi Masyarakat Dikawasan Bukit Cinta Rawa Pening Kabupaten Semarang. Fakultas Teknik Universitas Diponegoro.

Edi Susilo. 2010. Dinamika Struktur Sosial Dalam Ekosistem Pesisir. Malang : Universitas Brawijaya Press.

Noor, Juliansyah. 2011. Metodelogi Penelitian. Jakarta: Kharisma Putra Utama

Pitana, I Gede dan Putu G. Gayatri. 2005.Sosiologi Pariwisata. Yogyakarta: Penerbit Andi

Sobri, dkk., 2009, Pengelolaan Pendidikan, Yogyakarta: Multi Pressindo
Vijayanthi Sari, Ni Wayan. 2002. Pengelolaan Sampah di Kawasan Hotan Mangrove suwung Teluk Benoa Sebagai Upaya Kebersihan Lingkungan dan Pengembangan Ekowisata Mangrove. Semarang: Pascasarjana Universitas Diponogoro

Wibowo. 2007. Dampak Pengembangan Ekowisata Kawasan Wisata Gunung Merapi Merbabu Terhadap Perubahan Struktur Masyarakat. Surakarta: FISIP Universitas Sebelas Maret 